\title{
Does Regular Breakfast Cereal Consumption Help Children and Adolescents Stay Slimmer? A Systematic Review and Meta-Analysis
}

\author{
Anne de la Hunty ${ }^{a}$ Sigrid Gibson ${ }^{b}$ Margaret Ashwell ${ }^{a, c}$ \\ aAshwell Associates, Ashwell, bSig-Nurture Ltd, Guildford, c Oxford Brookes University, Oxford, UK
}

\author{
Key Words \\ Breakfast cereals · Obesity · Prevention · Children · Adolescents
}

\begin{abstract}
Objective: To review systematically the evidence on breakfast cereal consumption and obesity in children and adolescents and assess whether the regular consumption of breakfast cereals could help to prevent excessive weight gain. Methods: A systematic review and metaanalysis of studies relating breakfast cereal consumption to BMI, BMI z-scores and prevalence of obesity as the outcomes. Results: 14 papers met the inclusion criteria. The computed effect size for mean BMI between high consumers and low or non-consumers over all 25 study subgroups was $-1.13 \mathrm{~kg} / \mathrm{m}^{2}(95 \% \mathrm{CI}-0.81,-1.46, \mathrm{p}<0.0001)$ in the random effects model, which is equivalent to a standardised mean difference of 0.24 . Adjustment for age and publication bias attenuated the effect sizes somewhat but they remained statistically significant. The prevalence and risk of overweight was lower in children and adolescents who consume breakfast cereals regularly compared to those who consume them infrequently. Energy intakes tended to be higher in regular breakfast cereal consumers. Conclusion: Overall, the evidence reviewed is suggestive that regular consumption of breakfast cereals results in a lower BMI and a reduced likelihood of being overweight in children and adolescents. However, more evidence from long-term trials and investigations into mechanisms is needed to eliminate possible confounding factors and determine causality.

Copyright $\odot 2013$ S. Karger GmbH, Freiburg
\end{abstract}

\section{Introduction}

Franz Kafka's observation in his novel, Metamorphosis, that 'breakfast is the most important meal of the day' [1] has become deeply ingrained in the public mind. Indeed, no other meal has been the subject of as much research into its possible benefits. Nevertheless, it is still uncertain whether the possible benefits of breakfast are due to the particular types 
of food consumed or whether it is the timing of the meal which is important. Eating wholegrain breakfast cereals has been associated in prospective studies with lower risks of cardiovascular disease (CVD) and total mortality, diabetes, hypertension and weight gain in men [2-4]. Other studies have found that eating breakfast cereals regularly is associated with better micronutrient intakes and a healthier macronutrient profile [5]. However, not all breakfast meal types are associated with health benefits [6]. In 2007, we published the evidence from a systematic review for a relationship between regular breakfast cereal consumption and mean BMI, weight gain and risk of obesity. We concluded that, while there was consistent evidence of an inverse association between them, there was limited evidence for any proposed mechanism and that the observed association might have arisen from confounding [7].

Since that review, a number of new studies in children and adolescents have been published. Adolescence is a time when breakfast skipping becomes more common [8], and eating habits laid down during this growing period are likely to continue into adulthood. These studies therefore offer the possibility of looking at the relationship between breakfast cereal consumption and better energy balance in the context of a different physiological state to that in adults. Our focus in this review is on the prevention of obesity in children and adolescents. Whilst there are intervention studies that have looked at the effectiveness of using additional breakfast cereals as a meal replacement strategy for weight loss in children [9], we decided to limit our review to breakfast cereals eaten at breakfast time, insofar as it was possible to distinguish this, in order to look at the effectiveness of this potential simple sustainable dietary strategy for the long-term prevention of excessive weight gain.

We followed the AMSTAR guidelines [10] in compiling this review which require systematic reviews to have an a priori design, carry out duplicate study selection and data abstraction, tabulate the characteristics of included studies, assess the scientific quality of the included studies, use appropriate methods to combine data, examine the likelihood of publication bias and document conflicts of interest.

\section{Search Protocol}

\section{Search Strategy}

Three databases were searched for relevant papers published since 1990: Medline and Embase were searched in November 2011, and the Cochrane Central Register of Controlled Trials was searched in February 2012.

The exposure search terms used were 'breakfast cereals' and 'ready-to-eat-cereals' (RTEC). The outcome search terms were: 'weight', 'body mass index', 'BMI', 'weight gain', 'overweight', 'obesity' and 'adiposity'. All combinations of exposure and outcome terms were searched and duplicate references removed. The title and abstract of all identified papers were retrieved and imported into Endnote. Recent reviews [11,12] and included publications were also hand-searched for additional references.

\section{Study Selection}

Two reviewers (AdlH and MA) independently reviewed and selected relevant studies from the title and abstracts of the identified papers according to previously agreed inclusion and exclusion criteria. Any disagreement was discussed and resolved. The full text of the paper was obtained when it was unclear from the abstract whether it should be included. 
de la Hunty et al.: Does Regular Breakfast Cereal Consumption Help Children and Adolescents Stay Slimmer? A Systematic Review and Meta-Analysis

Table 1. The numbers of papers excluded by exclusion criteria

Exclusion criteria (from 160 potentially relevant papers)

Not a primary study

Not in humans

Does not look at breakfast cereals

Does not have BMI, \% overweight or obese or weight gain as an outcome

Uses breakfast cereal as the vehicle for another intervention

Includes additional breakfast cereals consumed other than at breakfast time

Not in children or adolescents

Included Papers

Number of papers excluded

5

18

9

97

6

4

7

14

\section{Inclusion Criteria}

- Primary studies in humans, either cross-sectional, prospective or intervention, published in peer-reviewed journals.

- Studies looking at the effect of breakfast cereals specifically.

- Outcomes include either BMI, \% overweight or obese, weight gain.

- Subjects include children or adolescents up to age 18.

\section{Exclusion Criteria}

- Abstracts, reviews, position statements, guidelines, editorials, case reports etc.

- Studies only in adults.

- Studies only looking at breakfast.

- Studies using breakfast cereal as the vehicle for another intervention, for example the effect of breakfast cereals with and without soluble fibre on serum cholesterol levels.

- Studies which looked at the effect of an additional serving of breakfast cereals or snack bars at a time of day other than early morning as a means of weight loss.

The searches of the three databases and recent reviews identified a total of 160 potentially relevant studies. The numbers of studies excluded at each stage is shown in table 1 . A total of 14 studies remained after the selection process. Full papers were obtained for these.

\section{Characteristics of Included Studies}

The studies included 11 cross-sectional studies [5, 13-22], 2 prospective studies [8, 23] and one intervention study [25]. See table 2 for details of individual studies.

The majority of the studies were carried out in the USA but other studies were performed in Greece, UK, Spain, Mexico and Sweden. Only four studies were included in our previous review $[8,13,16,20]$. Methods of dietary assessment included 24-hour recalls (5 studies), 3-, 7- or 14-day food records or diaries ( 5 studies), semi-quantitative food frequency questionnaires ( 3 studies), 7-day weighed food intakes ( 2 studies) and diet history (1 study). Breakfast cereal consumption was expressed in terms of frequency of consumption in 7 studies $[8,13,17$, $18,23]$. These studies divided consumers into between $3[13,17]$ and $6[18]$ bands of consumption.

Nine of the studies were secondary analyses of existing datasets, for example national dietary surveys, including the Diets of British Schoolchildren [16], the National Diet and Nutrition Survey (4-18 years) [5] and NHANES surveys from various years [14, 15, 22]. The two prospective studies were a further analysis of the National Heart, Lung and Blood Institute Growth and Health (NHLBIGH) study [8] and a prospective analysis of the Dietary Inter- 
de la Hunty et al.: Does Regular Breakfast Cereal Consumption Help Children and Adolescents Stay Slimmer? A Systematic Review and Meta-Analysis

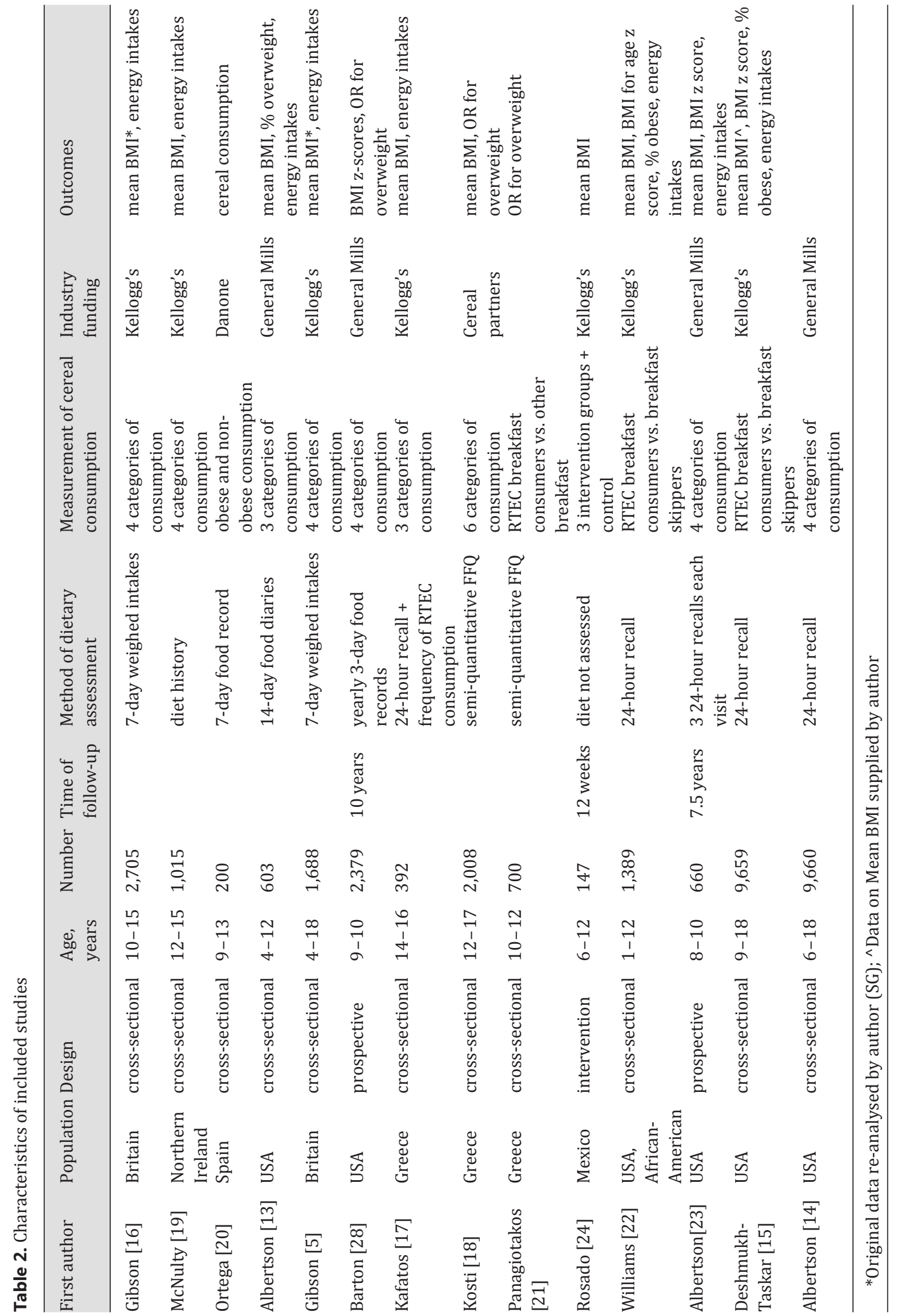


de la Hunty et al.: Does Regular Breakfast Cereal Consumption Help Children and

Adolescents Stay Slimmer? A Systematic Review and Meta-Analysis

vention Study in Children (DISC) dataset [23].The controlled 12-week trial randomised 147 children at risk of overweight or overweight and aged 6-12 years to 3 intervention groups and a control group, looking at the effect of eating either 1 dose of RTEC a day, 2 doses a day, 1 dose a day with weekly nutritional education or no intervention on BMI [24]. This trial was included because it had an arm of the study which looked at the effect of just one dose of RTEC a day.

13 of the 14 studies were funded by breakfast cereal manufacturers [5, 8, 13-20, 22-24]. For this reason we tested for publication bias (see later).

\section{Quality of Included Studies Assessed}

The scientific quality of the included studies was assessed independently by two reviewers (AdlH and MA) using an adapted form of the quality assessment questionnaire for observational studies included in the EFSA Health Claims submission guidance. The factors determining whether a study scored 'yes', 'partially' or 'no' were defined a priori (table 3).

Most of the studies were observational cross-sectional studies which are unable to determine causality and are potentially subject to confounding and reverse causality. The publications from the two separate prospective studies were of better quality while the one randomised intervention trial which met the inclusion criteria was only 12 weeks in duration and could only address the question of weight loss, and not the long-term prevention of weight gain. In our view, few studies adequately adjusted for potential confounding. Age is an important confounder as the frequency of breakfast eating declines with age and BMI tends to increase with age thus potentially giving rise to inverse associations that are spurious. Studies with large age bands which do not adjust for age (or do not use BMI z-scores) are especially likely to be confounded. Smoking, alcohol consumption, socio-economic status, physical activity and dairy consumption are all potential confounders for which few studies adequately adjusted.

Another potential confounder, for which none of the studies in this review attempted to control, is dieting. Dieting, and skipping breakfast as a means of reducing energy intake, is likely to be more common in overweight children and adolescents. Obesity could therefore be the cause of the breakfast skipping rather than the other way around. One prospective study of eating habits among teenagers found that a significant association between breakfast skipping and BMI was attenuated and became non-significant after adjusting for weightrelated behaviour [25].

\section{Analysis of Data}

Data from all publications were extracted by one reviewer (AdlH). Data on each outcome for the highest/most frequent consumer and the lowest/least frequent or non-consumer were recorded, along with values for the standard deviation, standard error or $95 \%$ confidence intervals and significance level reported.

\section{BMI and BMI z-Scores}

Nine cross-sectional studies [5, 13-19, 22], 1 prospective study [23] and 1 intervention trial [24] reported mean BMI according to breakfast cereal consumption. A further crosssectional study [20] reported breakfast cereal consumption according to BMI status. For the 2 British studies $[5,16]$ original data were re-analysed to provide the necessary BMI values 
Table 3. Assessment of study quality

[5] [19] [20] [13] [16] [9] [17] [18] [21] [24] [22] [23] [15] [14]

Power calculations performed

Was study adequately powered

Baseline characteristics of subjects reported

Subjects inclusion and exclusion criteria y

specified (or in original survey)

Exposure ascertained with reliable method

Information on the distribution of exposure(s)

Definition of outcome explicit

Outcome reliably assessed and validated

Information on background dietary habits provided

Information on physical activity provided

Information on smoking/alcohol drinking provided

Dose-response assessed

Adequate adjustment for the effects of confounding variables

Statistical methods adequately described

Outcome assessors blinded to exposure status

Appropriate duration of follow-up for outcome to occur

Information on loss to follow-up provided

Design includes control group

Control and intervention group(s)

comparable at baseline for relevant risk factors/outcome variables

Blinding of subjects

Compliance of subjects with the intervention reported

Analyses include an intention to treat analysis

Maximum score cross-sectional study $=14$

Maximum score prospective study $=17$

Maximum score intervention study $=20$

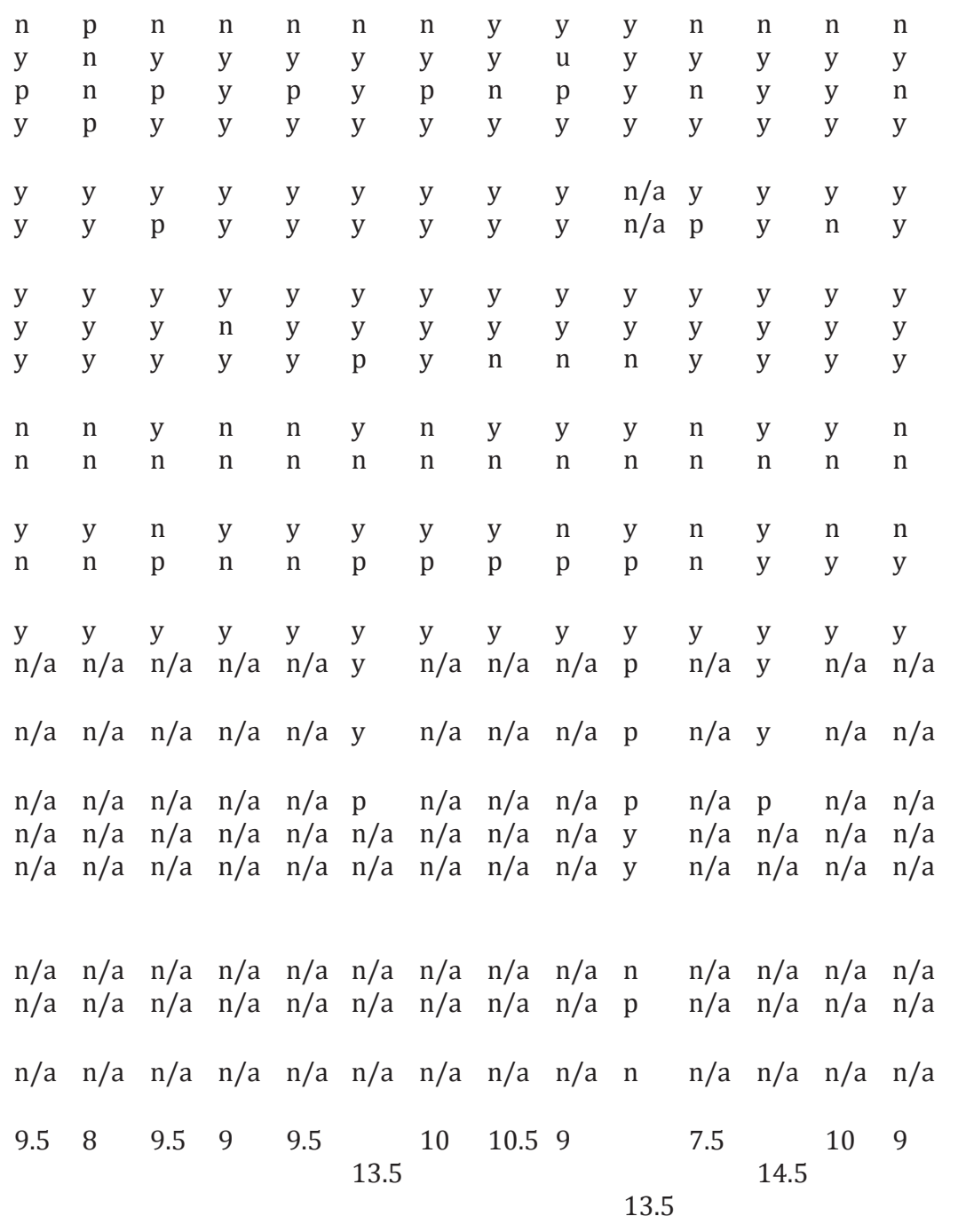

(means and standard deviations) for the same cereal consumption categories used in most of the other studies (non-consumers vs. $>40 \mathrm{~g}$ breakfast cereal/day). For the NDNS data, BMI z-scores were also computed and used in the supplementary analysis. Data on mean BMI was obtained from the authors of one study which only reported BMI z-score [15]. BMI z-scores were also reported by 3 cross-sectional studies $[14,15,22]$ and 2 prospective studies $[8,23]$.

\section{Cross-Sectional Studies}

The 9 cross-sectional studies with data on mean BMI gave a total of 25 separate subgroups in which the overall results were broken down into smaller age bands and/or single sex groups. These data were combined in a meta-analysis. 
de la Hunty et al.: Does Regular Breakfast Cereal Consumption Help Children and Adolescents Stay Slimmer? A Systematic Review and Meta-Analysis

\section{Data Analysis}

Meta-analysis was performed using comprehensive meta-analysis software (CMA $\vee 2$ : Biostat Inc. USA). Meta-analysis uses a weighted average of the results, in which the larger and more precise studies have more influence than the smaller ones. Results are shown in the form of schematic plots (Forest plots), which illustrate the size and direction of effect for each study and the weighted effect of all studies combined, with 95\% (lower and upper) confidence limits (CL). We used subgroup as the unit of analysis in order to explore differences between age groups within studies. The random effects model was chosen, as this assumes that the underlying effect may vary for each population subgroup and is more appropriate where heterogeneity is present $[26,27]$. Statistical significance of the overall pooled effect was based on $\mathrm{p}<0.05$.

\section{Results of Meta-Analysis}

The computed effect size for mean BMI between high consumers and low/non-consumers over all 25 study subgroups was $-1.13 \mathrm{~kg} / \mathrm{m}^{2}(95 \% \mathrm{CI}-0.81,-1.46 ; \mathrm{p}<0.0001)$ in the random effects model (fig. 1). This is equivalent to a standardised mean difference of 0.24 . Although an effect size of 0.24 is weak, the difference in mean BMI of over $1 \mathrm{~kg} / \mathrm{m}^{2}$ is arguably of clinical significance. There was wide dispersion but the value of the $\mathrm{I}^{2}$ statistic (69.55) indicated that nearly $70 \%$ of the observed variation between studies was real. This most likely reflects varied classification of cereal consumption, other differences in diet and life-style between populations and the use of BMI as a metric, which varies with age. No effect of study quality was seen in a meta-regression of study quality on mean BMI (data not shown). Sensitivity analysis was undertaken to explore the influence of different studies. Removal of one small study with the largest effect size [13] reduced the mean BMI difference to $-0.98 \mathrm{~kg} / \mathrm{m}^{2}(-1.29,-0.66)$, still highly significant $(\mathrm{p}<0.0001)$. Two subgroups with the youngest children $(2-5$ years [22] and $4-6$ years [5]) were non-significant for BMI but were of low power as few children of that age were non-consumers. Otherwise there was no clear association between age group and effect size.

A sensitivity analysis comparing the effect sizes for mean BMI and BMI z-scores in the four studies where data on both outcomes were available found that adjusting BMI for age attenuated the effect size from $-0.16(-0.12,-0.19)$ to $-0.11(-0.06,-0.17)$, still significantly different from zero $(\mathrm{p}<0.0001)$. Thus some, but not all, of the observed association between breakfast cereal consumption and lower BMI is explained by the fact that older children are less likely to eat breakfast than younger children and BMI tends to track upwards with age.

\section{Prospective and Intervention Studies}

Mean BMI in one of the prospective studies [23] was significantly lower in boys consuming breakfast cereals most frequently over 7.5 years, but not in girls(table 4 ). The difference was small, however, and amounted to $0.33 \mathrm{~kg} / \mathrm{m}^{2}$. Mean BMI z-scores in this study were not significantly different between low and high consumers for either boys or girls. The other (larger) prospective study in girls found a significant correlation between days eating cereal and BMI z-scores over 10 years amounting to $0.015 \mathrm{BMI} z$-score per day eating cereal out of a possible 3 days [8].

In the intervention trial [24], one arm compared the effect on BMI of giving 46 overweight children aged 6-12 years a daily serving of RTEC with 45 similar children given the daily serving of RTEC and a weekly session of nutrition education and with 39 other children who 


\begin{tabular}{|c|c|c|c|c|c|c|c|c|c|c|c|c|}
\hline \multirow[t]{2}{*}{ Model } & \multirow[t]{2}{*}{ Study name } & \multirow[t]{2}{*}{ Outcome } & \multirow{2}{*}{ Subgroup with in stud } & \multicolumn{4}{|c|}{ Statistics for each study } & \multirow[b]{2}{*}{$\mathrm{p}$-Value } & \multirow{2}{*}{\multicolumn{3}{|c|}{ Difference in means and $95 \% \mathrm{Cl}$}} & \\
\hline & & & & $\begin{array}{l}\text { Diff e rence } \\
\text { in means }\end{array}$ & $\begin{array}{c}\text { Lower } \\
\text { limit }\end{array}$ & $\begin{array}{l}\text { Upper } \\
\text { limit }\end{array}$ & Z-Value & & & & & \\
\hline & Gibson, 1995 & BMI & $10-11$ years_ $F$ & -0.40 & -1.06 & 0.26 & -1.185 & 0.236 & & & & \\
\hline & Gibson, 1995 & BMI & $10-11$ years_M & -0.70 & -1.38 & -0.02 & -2.008 & 0.045 & & & & \\
\hline & Gibson, 1995 & BMI & $14-15$ years_ $F$ & -1.00 & -1.91 & -0.09 & -2.146 & 0.032 & & & & \\
\hline & Gibson, 1995 & BMI & $14-15$ years_M & -0.27 & -0.80 & 0.26 & -1.004 & 0.315 & & & & \\
\hline & McNulty, 1996 & BMI & 12 years_F & -0.40 & -2.09 & 1.29 & -0.464 & 0.643 & & & & \\
\hline & McNulty, 1996 & BMI & 12 years_M & -1.40 & -2.92 & 0.12 & -1.807 & 0.071 & & & & \\
\hline & McNulty, 1996 & BMI & 15 years_F & -0.80 & -2.81 & 1.21 & -0.779 & 0.436 & & & & \\
\hline & McNulty, 1996 & BMI & 15 years_M & 0.00 & -1.86 & 1.86 & 0.000 & 1.000 & & & & \\
\hline & Albertson, 2003 & BMI & $10-12$ years & -2.90 & -4.23 & -1.57 & -4.287 & 0.000 & & & & \\
\hline & Albertson, 2003 & BMI & $4-6$ years & -2.30 & -3.55 & -1.05 & -3.592 & 0.000 & - & & & \\
\hline & Albertson, 2003 & BMI & $7-9$ years & -2.60 & -4.12 & -1.08 & -3.358 & 0.001 & & & & \\
\hline & Gibson, 2003 & BMI & $11-14$ years & -0.70 & -1.64 & 0.24 & -1.460 & 0.144 & & & & \\
\hline & Gibson, 2003 & BMI & $15-18$ years & -1.40 & -2.51 & -0.29 & -2.480 & 0.013 & & & & \\
\hline & Gibson, 2003 & BMI & $4-6$ years & 0.40 & -0.59 & 1.39 & 0.791 & 0.429 & & & & \\
\hline & Gibson, 2003 & BMI & $7-10$ years & -0.60 & -1.57 & 0.37 & -1.217 & 0.224 & & 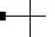 & & \\
\hline & Kafatos, 2005 & BMI & $14-16$ years & -1.50 & -2.84 & -0.16 & -2.200 & 0.028 & & & & \\
\hline & Kosti, 2008 & $\mathrm{BMI}$ & $12-17$ years_F & -2.30 & -3.33 & -1.27 & -4.373 & 0.000 & $=$ & & & \\
\hline & Kosti, 2008 & BMI & $12-17$ years_M & -1.40 & -2.28 & -0.52 & -3.123 & 0.002 & & & & \\
\hline & Williams, 2008 & BMI & $2-5$ years & 0.10 & -0.43 & 0.63 & 0.369 & 0.712 & & & & \\
\hline & Williarns, 2008 & BMI & $6-12$ years & -2.00 & -3.01 & -0.99 & -3.871 & 0.000 & & & & \\
\hline & Deshmukh-Taskar, 2010 & BMI & $14-18$ years & -1.47 & -2.11 & -0.83 & -4.522 & 0.000 & & & & \\
\hline & Deshmukh-Taskar, 2010 & BMI & $9-13$ years & -1.14 & -1.77 & -0.51 & -3.558 & 0.000 & & & & \\
\hline & Albertson, 2011 & BMI & $6-18$ years hisugar & -1.64 & -2.36 & -0.92 & -4.488 & 0.000 & & & & \\
\hline & Albertson, 2011 & BMI & $6-18$ years low sugar & -1.55 & -2.61 & -0.49 & -2.869 & 0.004 & & & & \\
\hline & Albertson, 2011 & BMI & $6-18$ years medsugar & -1.65 & -2.77 & -0.53 & -2.898 & 0.004 & & & & \\
\hline Fixed & & & & -0.96 & -1.13 & -0.78 & -10.633 & 0.000 & 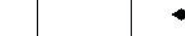 & & & \\
\hline \multirow[t]{3}{*}{ Random } & & & & -1.13 & -1.46 & -0.81 & -6.747 & 0.000 & & & & \\
\hline & & & & & & & & & -4.00 & 0.00 & 2.00 & 4.00 \\
\hline & & & & & & & & & Favours high cereal & \multicolumn{3}{|c|}{ Favours low cereal } \\
\hline
\end{tabular}

Fig. 1. Forest plot of BMI difference between high and low consumers of RTEC.

received no treatment. A 4th arm of 48 children received two servings of RTEC to be consumed at breakfast and lunchtime. Only the group receiving the nutrition education in addition to the daily RTEC showed a significant reduction in BMI compared to the controls after 12 weeks $(-0.9$ units $(-1.2,-0.5))$. The group receiving one serving of RTEC/day showed no change in BMI after 12 weeks $(0.1(-0.3,0.4))$. However, the trial was only 12 weeks long, and so it is difficult to draw conclusions regarding the long-term effect on the prevention of excessive weight gain from this study.

\section{Prevalence and Odds Ratios for Overweight and Obesity}

Six cross-sectional studies [13-15, 18, 21, 22] and one prospective study [8] reported either the prevalence of overweight and/or obesity or the odds ratio (OR) of being overweight or obese according to breakfast cereal consumption (table 5).

The prevalence of overweight or obesity was significantly lower in those eating breakfast cereals most regularly in 11 of the 12 comparisons reported in these studies. Differences in prevalence ranged from 5 percentage points to over 30 percentage points. The OR for being overweight or obese was also significantly lower in 3 of the 4 comparisons reported directly, including one prospective study [28]. The other prospective study did not report ORs for overweight or obesity, although the raw data would have been available [23]. 
de la Hunty et al.: Does Regular Breakfast Cereal Consumption Help Children and

Adolescents Stay Slimmer? A Systematic Review and Meta-Analysis

The ORs (including those calculated from the prevalence figures given) ranged from 0.19 to 0.87 . The weakest effect $(0.87)$ was found in the prospective study and this is likely to be a better reflection of the true value [8]. Studies which did not adjust for age [13, 22] tended to show stronger effects than studies which did $[15,18]$.The range of ORs reported was similar irrespective of whether the $85 \%$ cut-off or the $95 \%$ cut-off for BMI was used, suggesting a similar increased risk for overweight and obesity in those consuming breakfast cereals less frequently or not at all.

\section{Energy Intakes}

Energy intakes were reported according to cereal consumption in 8 cross-sectional studies $[5,13,15-17,19,22,23]$ and in 1 prospective study [23]. They were significantly higher in those consuming breakfast cereals most frequently in 12 out of the 20 comparisons and non-significantly higher in 5 others (table 6). Although few of these studies adjusted for age in their analyses, in this case, confounding by age is likely to weaken the observed association rather than strengthen it since older children are less likely to consume breakfast cereals regularly but have higher energy intakes.

\section{Discussion}

The finding that children and adolescents who consume breakfast cereals regularly are slimmer and are less likely to be overweight than children and adolescents who consume breakfast cereals infrequently or not at all is consistent with our previous review and others $[7,12,29]$. In particular, a meta-analysis of skipping breakfast and prevalence of overweight in Asian and Pacific regions found a pooled OR of overweight or obesity for the lowest versus highest category of breakfast frequency of $1.75>(1.57-1.95)(p<0.001)$ which is within the range we found [29]. Nevertheless, the question of whether it is a causal relationship remains. Confounding, for example by higher physical activity levels or dieting behaviour, is a plausible explanation. The consistently lower energy intakes of those consuming breakfast cereals less frequently supports the possibility that those who are already overweight are trying to lose weight by skipping breakfast. Thus reverse causality could be the explanation for the observed relationship between breakfast cereal consumption and lower BMI. Alternatively, those who are more physically active might be both more likely to eat breakfast and have a lower BMI. However, there is some evidence (discussed below) that breakfast cereal consumers might have lower energy intakes or higher energy expenditures which could provide a plausible mechanism for the observed relationship.

\section{Possible Mechanisms for Observed Effect}

\section{Lower Energy Intakes}

It is possible that the apparently higher energy intake of breakfast cereal consumers is an artefact of under-reporting of energy intakes by overweight subjects. This would result in spuriously higher energy intakes by breakfast consumers who are also more likely to be normal weight. A study in Swedish adolescents [30] found that a significantly negative correlation between total energy intakes and BMI changed to a significantly positive correlation when under- and over-reporters were excluded from the analysis. 


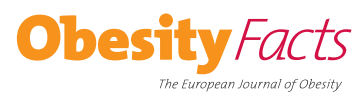

\begin{tabular}{l|l}
\hline Obes Facts 2013;6:70-85 & $\begin{array}{l}\text { (c) 2013 S. Karger GmbH, Freiburg } \\
\text { www.karger.com/ofa }\end{array}$ \\
\hline DOI: $10.1159 / 000348878$ &
\end{tabular}

de la Hunty et al.: Does Regular Breakfast Cereal Consumption Help Children and Adolescents Stay Slimmer? A Systematic Review and Meta-Analysis

Table 4. Results for mean BMI and BMI z-scores from prospective studies

\begin{tabular}{|c|c|c|c|c|c|c|c|c|c|}
\hline Reference & $\begin{array}{l}\text { Age, } \\
\text { years }\end{array}$ & $\begin{array}{l}\text { Follow-up } \\
\text { length, } \\
\text { years }\end{array}$ & Group & $\begin{array}{l}\text { Mean BMI of } \\
\text { lowest group } \\
\text { (standarderror) }\end{array}$ & $\begin{array}{l}\text { Mean BMI of } \\
\text { highest group } \\
\text { (standard error) }\end{array}$ & $\begin{array}{l}\text { Signifi- } \\
\text { cance }\end{array}$ & $\begin{array}{l}\text { Mean BMI z scores } \\
\text { of lowest group } \\
\text { (standard error) }\end{array}$ & $\begin{array}{l}\text { Mean BMI z scores } \\
\text { of highest group } \\
\text { (standard error) }\end{array}$ & $\begin{array}{l}\text { Signifi- } \\
\text { cance }\end{array}$ \\
\hline $\begin{array}{l}\text { Barton } \\
{[28]}\end{array}$ & $9-10$ & 10 & girls & not given & not given & & \multicolumn{2}{|c|}{$\beta=-0.015 /$ day out of 3} & $\mathrm{p}<0.01$ \\
\hline Albertson & $8-10$ & 7.5 & boys & $20.39(0.17)$ & 20.0 & $\mathrm{p}<0.01$ & $0.384(0.050)$ & 0.3 & ns \\
\hline$[24]$ & $8-10$ & 7.5 & girls & $19.55(0.17)$ & $19.61(0.18)$ & ns & $0.237(0.052)$ & $0.256(0.056)$ & ns \\
\hline
\end{tabular}

ns = Non-significant

Other studies have found that skipping breakfast leads to an increase in total energy intakes. For example, a 2-year follow-up study to a weight loss intervention trial in 11- to 16-year-olds found that total energy intakes increased as energy consumption at breakfast decreased. Snacking increased from almost none to $10 \%$ of energy, and total energy intakes increased by $171 \mathrm{kcal} /$ day [31]. Another, crossover intervention study investigated the effect of omitting breakfast for 2 weeks on energy intake, energy expenditure and insulin sensitivity in 10 healthy lean women [32]. This study found that eating breakfast lead to a significant reduction in reported total energy intakes $(-90 \mathrm{kcal} ; \mathrm{p}=0.001)$ and a significantly improved post-prandial insulin sensitivity, although there were no significant differences in weight over this short time period. Improved insulin sensitivity is associated in some, though not all, studies with increased satiety, reduced hunger and lower energy intakes and is a (negative) predictor of future weight gain [33].

\section{Higher Energy Expenditure}

Four studies found an inverse association between breakfast cereal consumption and adiposity even after controlling for energy intakes [14, 15, 23, 28]. The fact that many studies have failed to find lower energy intakes in breakfast cereal consumers also implies that any effect must be, at least in part, mediated through changes in energy expenditure, i.e., through increases in physical activity or metabolic rate.

A further analysis of the NHLBIG prospective study found that physical activity levels were higher in girls who consumed breakfast cereals regularly [34]. This raises the possibility that it is higher physical activity that is driving breakfast consumption. Alternatively, children who eat breakfast regularly might be more physically active because they feel more energetic, in which case physical activity would be a mediator in the causal pathway. The 5 studies in our review which did adjust for physical activity levels, however, all found a significant inverse association between breakfast cereal consumption, and a measure of adiposity remained after adjustment which suggests that the effects of breakfast cereals are independent of physical activity $[8,15,18,21,23]$.

Another potential mechanism by which breakfast cereal consumption could increase energy expenditure is via better insulin sensitivity in the morning. Circadian clocks regulate key biochemical pathways in metabolic tissues so that post-prandial responses differ with time of day [35]. Improved insulin sensitivity in the morning could increase the thermic effect of food (TEF) after breakfast [36, 37] thus increasing overall energy expenditure. However, the crossover intervention study discussed above which found impaired insulin 


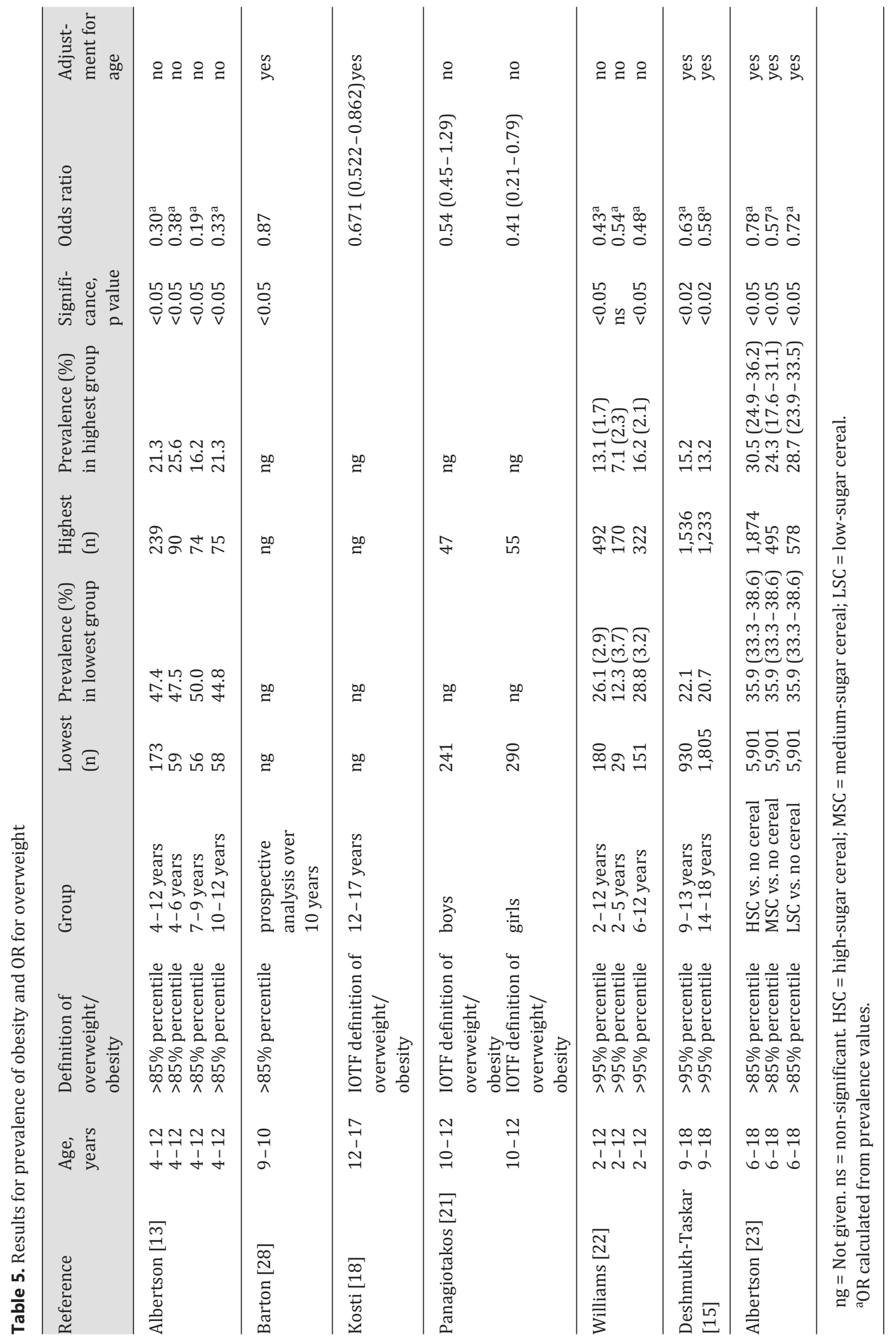


de la Hunty et al.: Does Regular Breakfast Cereal Consumption Help Children and Adolescents Stay Slimmer? A Systematic Review and Meta-Analysis

sensitivity after omitting breakfast for 2 weeks found no effect on TEF or resting metabolic rate [32]. It could be that the degree of insulin insensitivity produced in this study was not great enough to reduce TEF. The control of energy balance is a complex and finely tuned system. It is possible that synchronising energy intakes with the period of maximum insulin sensitivity might have greater effects on satiety and subsequent energy intake and expenditure.

\section{Breakfast or Breakfast Cereals?}

The question as to whether it is breakfast cereals specifically, or just eating (any) breakfast, which is associated with lower BMI also needs to be considered. In adults, a crosssectional study found that people who ate RTEC, cooked cereal or quick breads had a significantly lower BMI than those who skipped breakfast. However, those who ate 'meat and eggs', dairy products or 'fats and sweets' for breakfast did not [6]. Two studies in our review compared mean BMI and the prevalence of overweight between cereal consumers, those eating another type of breakfast and breakfast skippers. They found that the results for those eating 'other breakfasts' tended to be intermediate between cereal eaters and breakfast skippers $[15,22]$. The prospective study of girls aged 9 years at baseline found that the association with breakfast disappeared when breakfast cereal consumption was controlled for [8]. There is a suggestion therefore that the association is stronger for breakfast cereals, but without further analysis of the differences in energy and nutrient content of different types of breakfast no clear conclusions can be drawn.

\section{Publication Bias and Conflicts of Interest}

13 of the 14 studies in this review were funded by a breakfast cereal manufacturer, as was our review. Industry-funded nutrition-related scientific articles are more likely to find favourable conclusions than non-industry-funded articles with the possibility of bias being introduced in a variety of ways [38]. For reviews, the most relevant concerns are publication bias arising through non-significant or non-favourable results remaining unpublished and the selective choice of studies to be included in the review. Nevertheless, industry funding plays a critical role in the research process, particularly for studies which might give rise to a potential commercial advantage and for which public funding is arguably inappropriate. It is unlikely that many of the studies / secondary analyses in this review would have been carried out without industry funding, and yet, given the evidence base required in the health claims approval process, such research is both necessary and of potential benefit to the consumer. It is therefore important that there are clear guidelines to protect the integrity of such research and ensure transparency [39].

We addressed the possibility of bias in our review in a couple of ways. We minimised the possibility of biased study selection by following the AMSTAR guidelines for assessing the methodological quality of systematic reviews [10]. The possibility of publication bias in our dataset was assessed using a funnel plot and Duval's and Tweedie's method known as 'Trim and Fill' [40]. Using these parameters for the mean BMI analysis, the method suggests that a small number of studies were potentially missing and the standardised mean difference $(95 \% \mathrm{CL})$ for the combined studies was reduced from $0.24(-0.18,-0.30)$ to $0.18(-0.11$, $-0.25)$, though it remained significant $(\mathrm{p}<0.0001)$. Thus we feel our conclusions are robust, even after allowing for the fact that almost all the studies were funded by cereal manufacturers. 
de la Hunty et al.: Does Regular Breakfast Cereal Consumption Help Children and Adolescents Stay Slimmer? A Systematic Review and Meta-Analysis

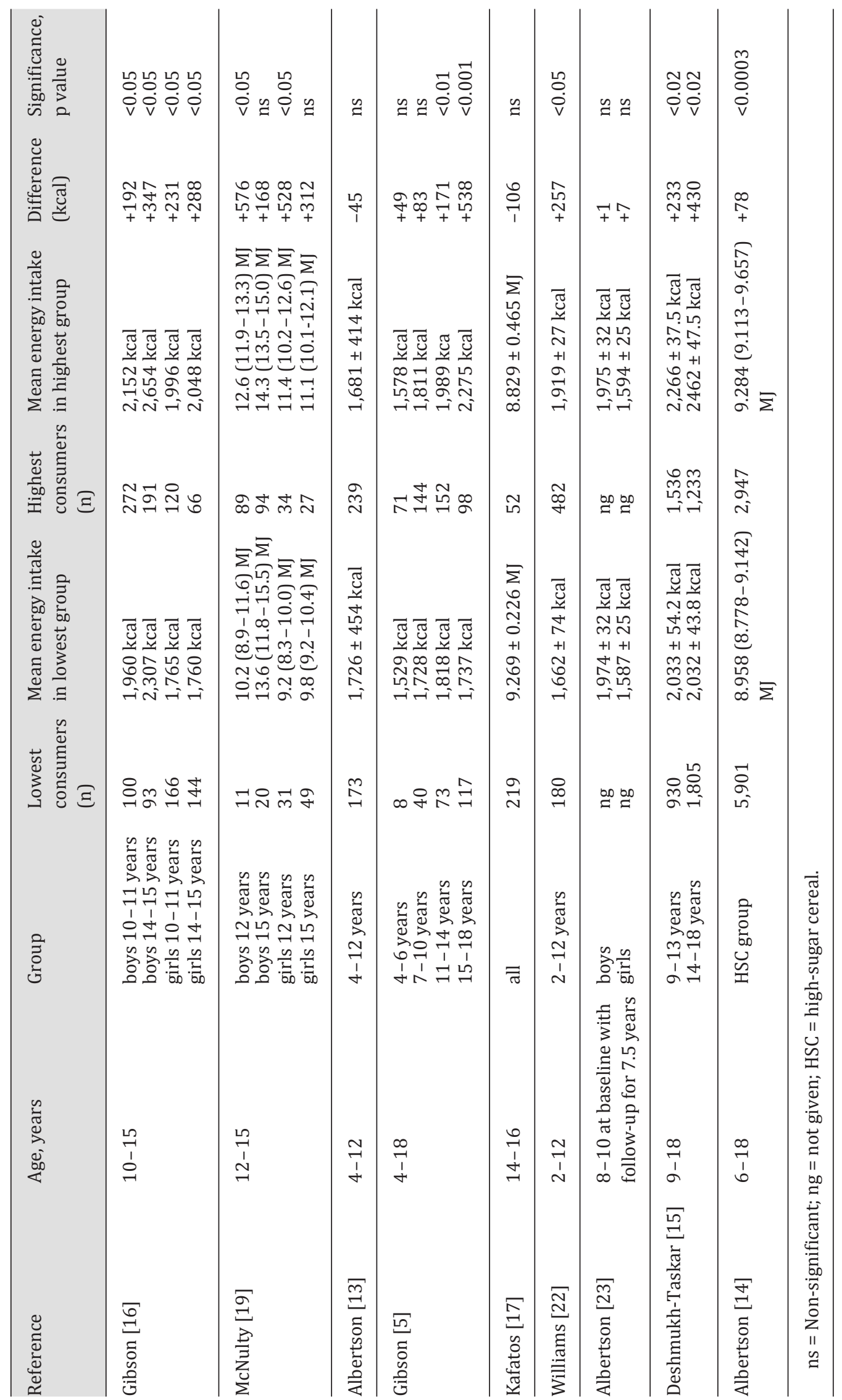


de la Hunty et al.: Does Regular Breakfast Cereal Consumption Help Children and Adolescents Stay Slimmer? A Systematic Review and Meta-Analysis

\section{Strengths and Limitations of Our Systematic Review and Meta-Analysis}

Our review has several strengths. We carried out a meta-analysis of all studies reporting mean BMI and BMI z-scores to quantify the size of the effect, something which has not been done previously. We also looked at the effect of quality of the studies and of adjusting for age and possible publication bias on the effect size. The evidence includes several large, nationally representative surveys and studies from a number of different countries and in different population groups which enhances the generalisability of our findings across different groups of people. Limitations of the review are that the evidence is mostly from cross-sectional studies which are potentially subject to confounding and reverse causality and that studies used a variety of methods for measuring breakfast cereal intake and defining what was included as breakfast cereal.

\section{Conclusions}

Evidence from two independent prospective cohorts and 11 cross-sectional studies has shown that children and adolescents who consume breakfast cereals regularly have a significantly lower mean BMI and are less likely to be overweight or obese than children and adolescents who consume breakfast cereals infrequently or not at all. Mean BMI was lower by around $1 \mathrm{~kg} / \mathrm{m}^{2}$, and the risk of overweight was reduced by at least $10 \%$ and possibly by up to $50 \%$ in those consuming breakfast cereals regularly. The size of these effects, though small, are of clinical significance and they were similar in children and adolescents. Adjustment for age and publication bias attenuated the effect sizes somewhat but they remained statistically significant.

However, the possibility of residual confounding by dieting, for example, or other explanations cannot be excluded and the mechanism involved is not clear, although it does not appear to be due to a straightforward reduction in total energy intake. Overall, the evidence reviewed is suggestive that regular consumption of breakfast cereals results in a lower BMI and a reduced likelihood of being overweight in children and adolescents. Further prospective studies with adequate adjustment for age, dieting behaviour and physical activity, in particular, are necessary to confidently exclude these factors as possible explanations. Ideally, adequately powered, randomised, controlled trials of a long enough duration to look at the prevention of excessive weight gain are necessary to determine whether eating breakfast cereals regularly does reduce the likelihood of excessive weight gain and the development of obesity in children and adolescents.

\section{Funding Statement}

This review was funded by The Kellogg Company (UK) but the authors are entirely responsible for the content of the review and followed established guidelines on financial conflicts and scientific integrity [39].

\section{Disclosure Statement}

The authors declared no conflict of interest. 
de la Hunty et al.: Does Regular Breakfast Cereal Consumption Help Children and Adolescents Stay Slimmer? A Systematic Review and Meta-Analysis

\section{References} different amounts of breakfast cereals: further analysis of data from the National Diet and Nutrition Survey of Young People aged 4 to 18 years. Publ Health Nutr 2003;6:815-820.

6 Cho S, Dietrich M, Brown CJ, Clark CA, Block G: The effect of breakfast type on total daily energy intake and body mass index: results from the Third National Health and Nutrition Examination Survey NHANES III. J Am Coll Nutr 2003;22:296-302.

7 de la Hunty A, Ashwell M: Are people who regularly eat breakfast cereals slimmer than those who don't? A systematic review of the evidence. Nutr Bull 2007;32:118-128.

- 8 Barton BA, Eldridge AL, Thompson D, Affenito SG, Striegel-Moore RH, Franko DL, Albertson AM, Crockett SJ: The relationship of breakfast and cereal consumption to nutrient intake and body mass index: the National Heart, Lung, and Blood Institute Growth and Health Study. J Am Diet Assoc 2005;105:1383-1389.

- 9 Rodearmel SJ, Wyatt HR, Barry MJ, Dong F, Pan D, Israel RG, Cho SS, McBurney MI, Hill JO: A family-based approach to preventing excessive weight gain. Obesity (Silver Spring) 2006;14:1392-1401.

-10 Shea BJ, Grimshaw JM, Wells GA, Boers M, Andersson N, Hamel C, Porter AC, Tugwell P, Moher D, Bouter LM: Development of AMSTAR: a measurement tool to assess the methodological quality of systematic reviews. BMC Med Res Methodol 2007;7:10.

-11 Rampersaud GC, Pereira MA, Girard BL, Adams J, Metzl JD: Breakfast habits, nutritional status, body weight, and academic performance in children and adolescents. J Am Diet Assoc 2005;105:743-760, quiz 761-762.

-12 Kosti RI, Panagiotakos DB, Zampelas A: Ready-to-eat cereals and the burden of obesity in the context of their nutritional contribution: are all ready-to-eat cereals equally healthy? A systematic review. Nutr Res Rev 2010; 23:314-322.

13 Albertson AM, Anderson GH, Crockett SJ, Goebel MT: Ready-to-eat cereal consumption: its relationship with BMI and nutrient intake of children aged 4 to 12 years. J Am Diet Assoc 2003;103:1613-1619.

14 Albertson AM, Thompson DR, Franko DL, Holschuh NM: Weight indicators and nutrient intake in children and adolescents do not vary by sugar content in ready-to-eat cereal: results from National Health and Nutrition Examination Survey 2001-2006. Nutr Res 2011;31:229-236.

-15 Deshmukh-Taskar PR, Nicklas TA, O’Neil CE, Keast DR, Radcliffe JD, Cho S: The relationship of breakfast skipping and type of breakfast consumption with nutrient intake and weight status in children and adolescents: the National Health and Nutrition Examination Survey 1999-2006. J Am Diet Assoc 2010;110:869-878.

-16 Gibson SA, Sullivan KRO: Breakfast cereal consumption patterns and nutrient intakes of British schoolchildren. J R Soc Health 1995;115:366-370.

17 Kafatos A, Linardakis M, Bertsias G, Mammas I, Fletcher R, Bervanaki F: Consumption of ready-to-eat cereals in relation to health and diet indicators among school adolescents in Crete, Greece. Ann Nutr Metab 2005;49: 165-172.

-18 Kosti RI, Panagiotakos DB, Zampelas A, Mihas C, Alevizos A, Leonard C, Tountas Y, Mariolis A: The association between consumption of breakfast cereals and BMI in schoolchildren aged 12-17 years: the VYRONAS study. Publ Health Nutr 2008;11:1015-1021.

19 McNulty H, Eaton-Evans J, Cran G, Woulahan G, Boreham C, Savage JM, Fletcher R, Strain JJ: Nutrient intakes and impact of fortified breakfast cereals in schoolchildren. Arch Dis Child 1996;75:474-481.

20 Ortega RM, Requejo AM, López-Sobaler AM, Quintas ME, Andrés P, Redondo MR, Navia B, López-Bonilla MD, Rivas T: Difference in the breakfast habits of overweight/obese and normal weight schoolchildren. Int J Vitam Nutr Res 1998;68:125-132.

-21 Panagiotakos DB, Antonogeorgos G, Papadimitriou A, Anthracopoulos MB, Papadopoulos M, Konstantinidou M, Fretzayas A, Priftis KN: Breakfast cereal is associated with a lower prevalence of obesity among 10-12year-old children: the PANACEA study. Nutr Metab Cardiovasc Dis 2008;18:606-612.

-22 Williams BM, O’Neil CE, Keast DR, Cho S, Nicklas TA: Are breakfast consumption patterns associated with weight status and nutrient adequacy in African-American children? Publ Health Nutr 2009;12:489-496.

-23 Albertson AM, Affenito SG, Bauserman R, Holschuh NM, Eldridge AL, Barton BA: The relationship of ready-toeat cereal consumption to nutrient intake, blood lipids, and body mass index of children as they age through adolescence (DISC Study). J Am Diet Assoc 2009;109:1557-1665.

-24 Rosado JL, del R Arellano M, Montemayor K, García OP, del C Caamaño M: An increase of cereal intake as an approach to weight reduction in children is effective only when accompanied by nutrition education: a randomized controlled trial. Nutr J 2008; 7:28.

-25 Timlin MT, Pereira MA, Story M, Neumark-Sztainer D: Breakfast eating and weight change in a 5-year prospective analysis of adolescents: Project EAT (Eating Among Teens). Pediatrics 2008;121:e638-645.

26 Egger M, Smith G: Meta-analysis: potentials and promise. BMJ 1997;315:1371-1374. 
Egger M, Smith G, Phillips A: Meta-analysis: principles and procedures. BMJ 1997;315:1533-1537. The relationship of breakfast and cereal consumption to nutrient intake and body mass index: the National Heart, Lung, and Blood Institute Growth and Health Study. J Am Diet Assoc 2005;105:1383-1389.

-29 Horikawa C, Kodama S, Yachi Y, Heianza Y, Hirasawa R, Ibe Y, Saito K, Shimano H, Yamada N, Sone H: Skipping breakfast and prevalence of overweight and obesity in Asian and Pacific regions: a meta-analysis. Prev Med 2011;53:260-267.

-30 Vågstrand K, Barkeling B, Forslund HB, Elfhag K, Linné Y, Rössner S, Lindroos AK: Eating habits in relation to body fatness and gender in adolescents- results from the 'SWEDES' study. Eur J Clin Nutr 2007;61:517-525.

-31 Rolland-Cachera MF, Thibault H, Souberbielle JC, Soulié D, Carbonel P, Deheeger M, Roinsol D, Longueville E, Bellisle F, Serog P: Massive obesity in adolescents: dietary interventions and behaviours associated with weight regain at 2 y follow-up. Int J Obes Relat Metab Disord, 2004;28:514-519.

-32 Farshchi HR, Taylor MA, Macdonald IA: Deleterious effects of omitting breakfast on insulin sensitivity and fasting lipid profiles in healthy lean women. Am J Clin Nutr 2005;81:388-396.

-33 Pannacciulli N, Salbe AD, Ortega E, Venti CA, Bogardus C, Krakoff J: The 24-h carbohydrate oxidation rate in a human respiratory chamber predicts ad libitum food intake. Am J Clin Nutr 2007;86:625-632.

-34 Albertson AM, Thompson D, Franko DL, Kleinman RE, Barton BA, Crockett SJ: Consumption of breakfast cereal is associated with positive health outcomes: evidence from the National Heart, Lung, and Blood Institute Growth and Health Study. Nutr Res 2008;28:744-752.

-35 Morgan L, Hampton S, Gibbs M, Arendt J: Circadian aspects of postprandial metabolism. Chronobiol Int 2003; 20:795-808.

-36 Ravussin E, Acheson KJ, Vernet O, Danforth E, Jéquier E: Evidence that insulin resistance is responsible for the decreased thermic effect of glucose in human obesity. J Clin Invest 1985;76:1268-1273.

-37 Ravussin E, Bogardus C, Schwartz RS, Robbins DC, Wolfe RR, Horton ES, Danforth E Jr, Sims EA: Thermic effect of infused glucose and insulin in man. Decreased response with increased insulin resistance in obesity and noninsulin-dependent diabetes mellitus. J Clin Invest 1983;72:893-902.

-38 Lesser LI, Ebbeling CB, Goozner M, Wypij D, Ludwig DS. Relationship between funding source and conclusion among nutrition-related scientific articles. PLoS Med 2007;4:e5.

-39 Rowe S, Alexander N, Clydesdale F, Applebaum R, Atkinson S, Black R, Dwyer J, Hentges E, Higley N, Lefevre M, Lupton J, Miller S, Tancredi D, Weaver C, Woteki C, Wedral E; International Life Sciences Institute (ILSI) North America Working Group on Guiding Principles. Funding food science and nutrition research: financial conflicts and scientific integrity. Nutr Rev 2009;67:264-272.

40 Borenstein M, Hedges L, Higgins J, Rothstein H: Introduction to Meta-Analysis. :Chichester, Wiley \& Sons, 2009. 